\title{
Additive Manufacturing in Construction of Electrical Machines - A Review
}

\author{
Rafal Wrobel and Barrie Mecrow
}

\begin{abstract}
Additive manufacturing (AM) has been undergoing dynamic development in recent years. The latest evolution of AM has been recognised as a key enabling technology in a wide range of applications, some of which include medical, aerospace and automotive industries. The use of AM opens new avenues for design solutions, otherwise challenging or impossible to realise when using more conventional techniques for manufacture. No- or low-material waste and high-flexibility are some of the attributes of modern AM. This paper aims to provide an overview of the existing examples of employing AM in construction of electrical machines. The paper reviews research and development work related to all integral components of an electrical machine assembly. These include active parts like coils/windings, electrical insulation, stator/rotor magnetic core packs, permanent magnets (PMs). The machine structural/mechanical and thermal management components are also discussed in the paper. Further to these, the authors make some comments/forecasts on how the AM could improve performance and manufacturability of the future electrical machines.
\end{abstract}

Index Terms-Additive manufacturing (AM), manufacturing techniques, electrical machines, machine assembly.

\section{INTRODUCTION}

$\mathrm{F}$ UNDAMENTALS of design and fabrication of electrical machines are governed by well understood processes, which were established over decades of developments. All progress related to modern day electrical machines has been driven by two fundamental factors: demand for 'more electric' technologies and subsequent research-developments. It is important to note that both factors are non-exclusive in setting the new development trends, either as a results of socioeconomic landscape or 'blue-sky' research. The research element is particularly interesting in the context of this paper. More specifically, developments of new designing methods, materials and manufacturing techniques, which had a profound impact on the evolution of electrical machines. Some of the examples denoting step changes in electrical machine technology include: advances in high-fidelity design techniques, e.g. modern computational electromagnetics, introduction of new materials like high-energy rare-earth permanent magnets (PMs) and evolution of manufacturing methods for high-volume applications. All the above mentioned examples are the building blocks of the modern 'design for application' of electrical machines.

AM has been successfully employed in a large variety of applications, which is evidenced by a plethora of press announcements and researcher publications [1]-[45]. The ability to create virtually unconstrained, three-dimensional (3D), no-waste, rapid-prototyping of parts and components is very attractive. The use of wide range of materials: plastics, ceramics, metal alloys and even organic-/bio-materials (bioink) places $\mathrm{AM}$ at the forefront of modern techniques for manufacture. Further to these, ability to scale up manufacture from a single prototype to high-volume, adds to the list of benefits of employing AM. An example here are large aerospace companies, which announced the use of AM for involume production [1], [2].

In this paper, the focus is placed on electrical machines, where materials like plastics, ceramics and metal alloys are of particular interest. The key electrical machine sub-assemblies fabricated using AM are discussed in consecutive sections of the paper. The examples include: coils/windings, elements of electrical insulation, stator/rotor magnetic core packs, PMs, motor housing/structural parts and elements for machine thermal management. The authors are aware of numerous activities related to AM of electrical machines worldwide, both on the commercial and academic side. The material gathered in this paper is limited to commercially insensitive, most of which is readily available, with appropriate references provided. As the level of technology maturity varies among the selected examples, the authors provide supplementary commentary to help navigate the large volume of information.

\section{AM TECHNIQUES}

The term 'AM', or the less precise synonymous '3D printing', is rather broad and encompasses a wide range of techniques. The common factor for all the techniques is that a manufactured part is made by layering of material/materials based on a digital model representation. The American Society for Testing and Standards (ASTM) formulated a set of standards categorising AM techniques by the specific manufacturing processes used. There are 7 types of AM [3]:

- vat photopolymerisation,

- material jetting,

- binder jetting,

- material extrusion,

- powder bed fusion, sheet lamination,

direct energy deposition.

Further to the above classification various other works on standardisation and roadmapping for AM have been ongoing [4], [5]. Powder bed fusion is the most relevant in the context of AM of electrical machines.

Rafal Wrobel and Barrie Mecrow are with Newcastle University, School of Engineering, Merz Court, Newcastle upon Tyne, NE1 7UR, UK (e-mails: rafal.wrobel@newcastle.ac.uk and barrie.mecrow@newcastle.ac.uk). 
Here, the manufacturing process includes the following techniques [3]:

- direct metal laser sintering (DMLS),

- electron beam melting (EBM),

- selective heat sintering (SHS),

- selective laser melting (SLM),

- $\quad$ selective laser sintering (SLS).

All listed methods use a laser or electron beam to induce fusion (sintering or melting) between particles of a plastic or metal powder, layer by layer. Also, each of the methods is suited to work with a set of particular materials, e.g. DMLS/SLS allows fabricating parts with metals alloys like: aluminium, titanium, steel, nickel, and cobalt-chrome. Due to the space limitations of this paper, the authors recommend publications like [6], where a more comprehensive overview of AM and related topics can be found.

\section{AM In CONSTRUCTION OF ELECTRICAL MACHINES}

When reviewing the available literature related to AM of electrical machines, it is clear that the technology maturity is relatively low at the moment [7]-[30]. This is particularly evident in the context of active components of an electrical machine assembly like magnetic or winding materials, which frequently offer poorer physical properties, compared with the existing solutions which are commonly used in construction of electrical machines [7]-[30]. With that being said, the research and development has been progressing fast with new improved AM techniques and materials reported on, e.g. dot forming technology (DFT) for high-precision improved productivity of metal AM [9] or AM of pure copper and precious metals [9]. It seems that in some areas practical industrial implementations of AM are well ahead of what is evidenced by research works. It is the authors belief that successful deployment of AM in manufacture of electrical machine is just a matter of time. It is interesting to observe that the majority of work related to the AM of electrical machines is focused on the individual machine components and materials [7]-[30], though, some attempts have been made to introduce a more holistic approach, where multiple parts are fabricated using AM [40], [44].

\section{A. Mechanical Assembly and Thermal Management}

As the mechanical properties of parts fabricated using AM are frequently comparable to that manufactured using more conventional methods, e.g. metal casting, is not a surprise that

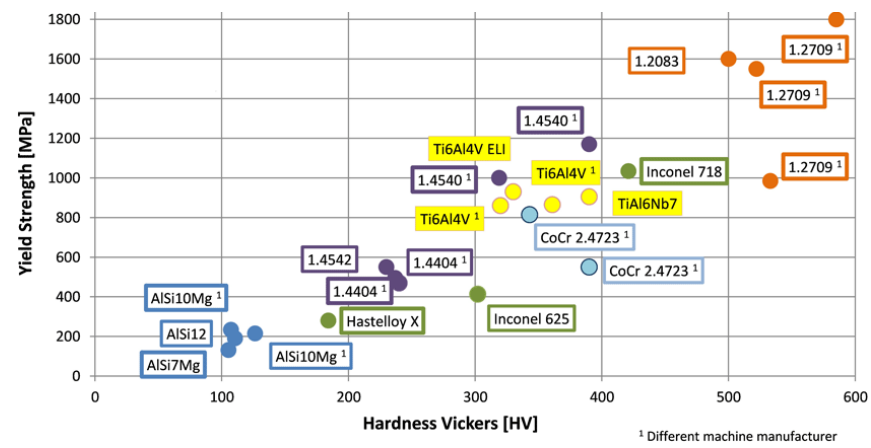

Fig. 1. Mechanical properties of metal alloys manufactured using AM with minimum values provided from the material data sheets - Powder Metallurgy Review [6]

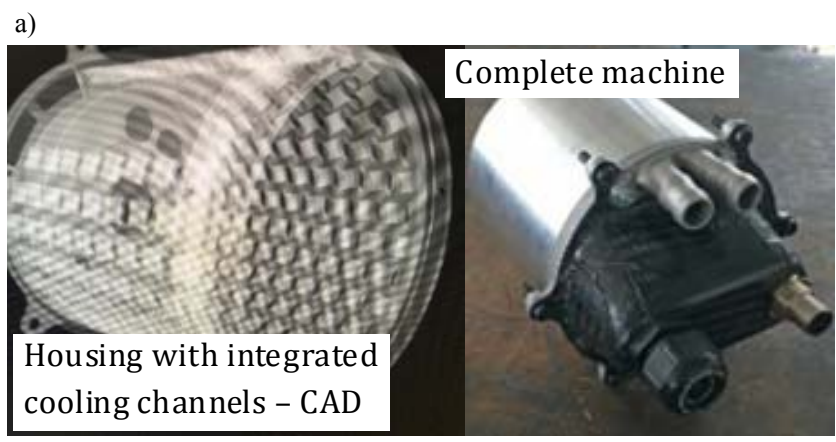

b)

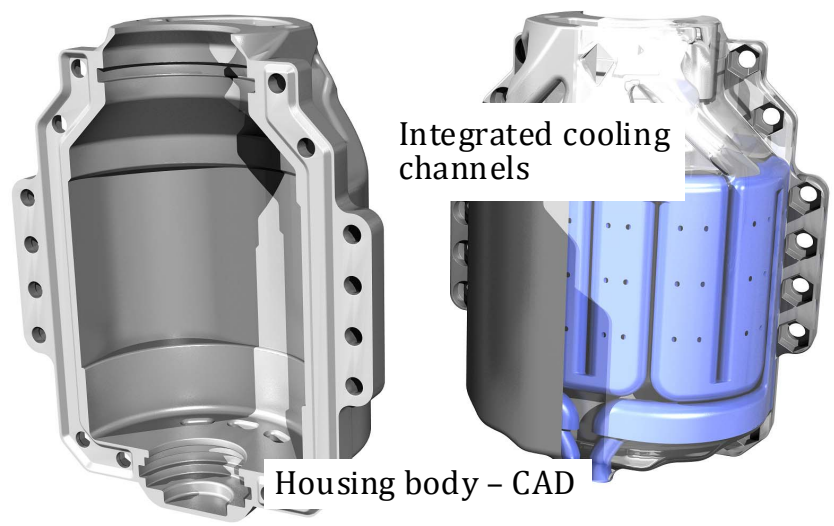

Fig. 2. Motor housing with integrated cooling channels, a) CAD and complete motor hardware - Technical University of Munich, TUfast Racing Team Formula Student [10], b) CAD - University of Nottingham [11]

the examples of mechanical/supporting parts of electrical machines seem to be the most mature. Fig. 1 presents selected mechanical properties for a set of metallic materials commonly used in AM. The nomenclature used in Fig. 1 refers to either chemical composition of a particular metal alloy, e.g. aluminium alloy AlSi10Mg, or DIN number, e.g. 1.2709 refers to tool steel (Marage 300) and 1.4540 stainless steel (15$5 \mathrm{PH})$, [6]. It is evident that there is some spread among the properties for different AM machine manufactures. This highlights the importance of ongoing work on standardisation of AM. It is important to note that the specific material properties can be altered/improved by appropriate processing, e.g. heat treatment, post-AM [6].

Fig. 2 presents examples of machine housing for electric vehicle (EV) applications. Here, the computer aided designs (CADs) and prototype hardware are shown. In both cases an unique integrated channel design for liquid cooling have been incorporated within the housing reducing the overall number of parts and improving an overall performance of thermal management system [10], [11]. In Fig 2a) the authors report $31 \%$ higher total mass flow and $20 \%$ improvement in total heat conduction and efficiency of the cooling system as compared with a more conventional design [10]. The authors do not provide details regarding the metal alloy used to fabricate the housing, but considering thermal conductivity of available alloys, it is most likely to be an aluminium alloy, e.g. AlSi10Mg.

Reducing the mass of structural parts of the motor assembly is another area where AM has been successfully used. Fig. 3 shows examples of rotor/shaft assemblies designed to be 
a)

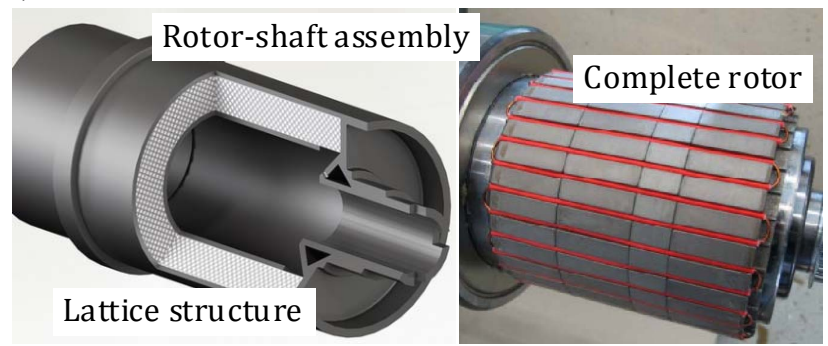

b)

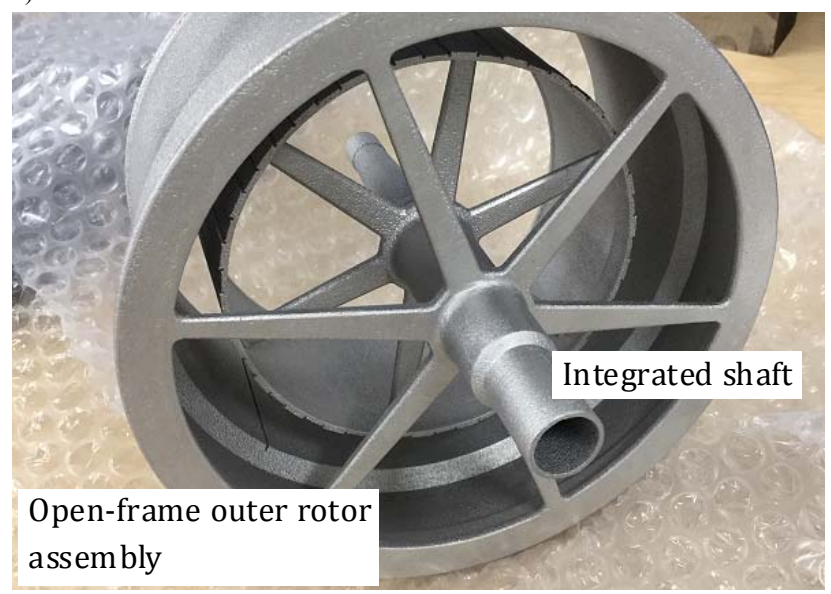

Fig. 3. Lightweight rotor/shaft assemblies, a) inner-rotor/shaft with lattice structure for PM motor application (CAD and complete rotor assembly) Paderborn University, Karlsruhe Institute for Technology and Leibniz University Hannover [12], b) outer- rotor/shaft for open-frame PM motor Newcastle University

fabricated using AM. Fig. 3a) presents a lightweight innerrotor/shaft assembly: CAD and practical implementation, together with permanent magnet (PM) array and damping coils [12]. The rotor/shaft was manufactured using tool steel (H13). Although the magnetic properties of $\mathrm{H} 13$ are relatively poor the authors show that by appropriate heat treatment these can be significantly improved to match properties of the existing soft magnetic composites (SMCs). More importantly by introducing a rotor/shaft with a lattice structure, the overall mass of the rotor was reduced by $25 \%$ and the moment of inertia decreased by $23 \%$, compared with a more conventional design. The next example here, Fig. 3b), shows mechanical the parts of an outer-rotor/shaft for an open-frame PM motor. Here, the intention was to provide a sufficient through air flow for removing heat from active parts of the motor assembly. The presented mechanical parts have been designed and manufactured using titanium alloy (Ti6Al4V) to provide an ultra-lightweight motor assembly.

It has been shown earlier that the existing techniques for removing heat from machine body greatly benefit from the use AM. As AM allows to rethink the manner in which electrical machines are thermally managed, less conventional solutions have been explored in some research. Fig. 4 presents a number of concept designs for enhanced heat removal specifically targeting motor stator/winding assembly. Fig. 4a) show a liquid cooled heat exchanger (HE) for direct heat evacuation from the winding body [13]. Here, HE is sharing the stator slot together with winding assembly. To assess the HE concept, the authors evaluated a number of alternative plastics including: ABS, Al-PC, CF-Nylon and PLA, with Al-PC being the preferred choice here [13]. A 44\% reduction in winding operating temperature as compared with no $\mathrm{HE}$ alternative stator/winding assembly has been reported.

A concept of air-cooled HE for extracting heat from the complete stator/winding assembly is shown in Fig. 4b), where fully assembled HE occupies the inner bore of the stator core pack. Such an arrangement provides a thermal path for an effective heat extraction. It is important to note that an outerrotor machine topology is considered here. The HE offers extremely high working surface area due to the application of design features possible only when using AM. Further to this, application of aluminium alloy ( $\mathrm{AlSi} 10 \mathrm{Mg}$ ) enables achieving the required performance of HE. Here, an equivalent thermal conductance of stator to $\mathrm{HE}$ is equal $470 \mathrm{~W} / \mathrm{m}^{2} \mathrm{~K}$ for $1.5 \mathrm{~m} / \mathrm{s}$ air flow at $20^{\circ} \mathrm{C}$.

a)

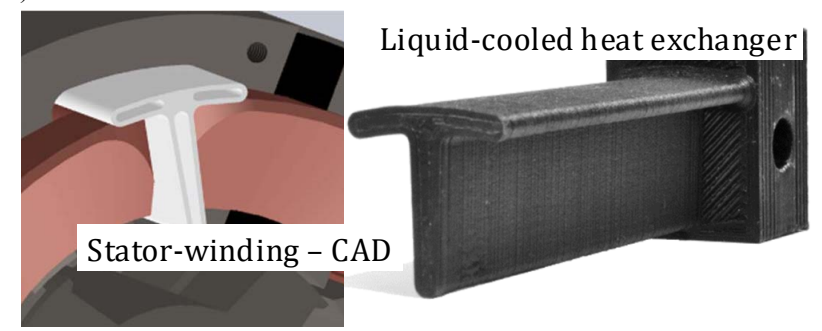

b)

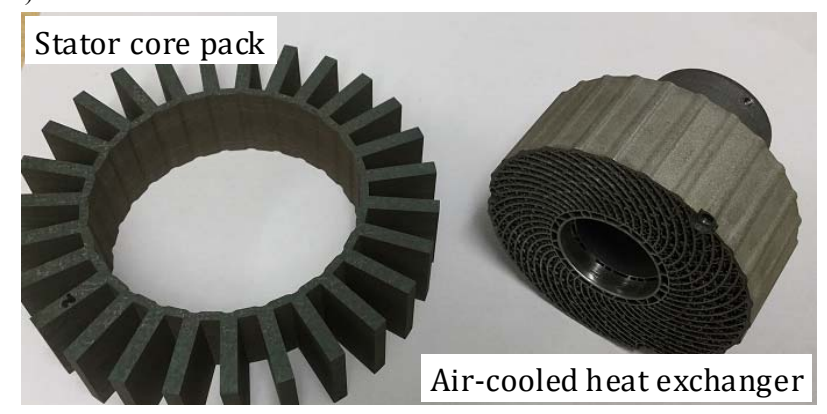

c)

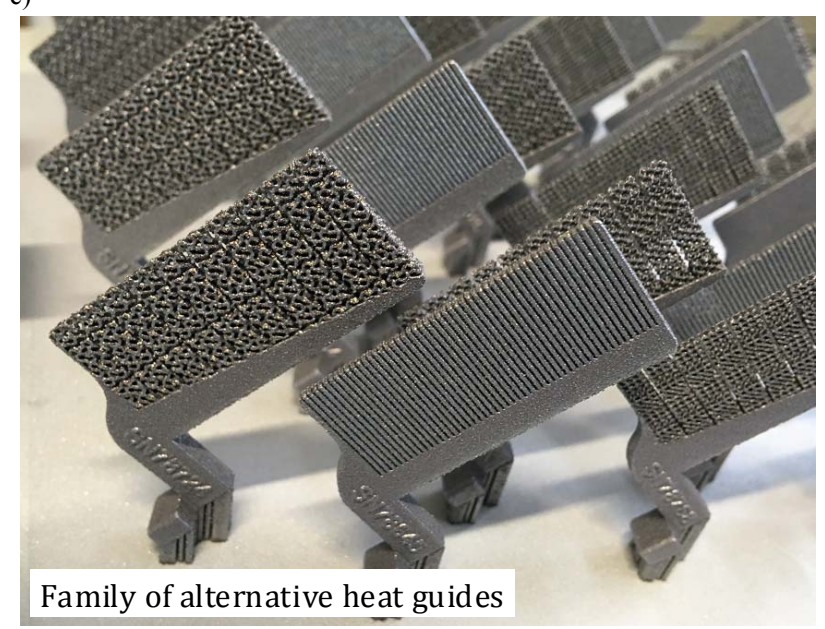

Fig. 4. Elements of thermal management systems for electrical machines, a) integrated liquid cooled HE (CAD of stator/winding together with $\mathrm{HE}$ and HE hardware) - University of Wisconsin-Madison [13], b) integrated aircooled HE/stator mechanical support (stator core pack and HE hardware) Newcastle University, c) set of HG for enhanced heat transfer in electrical machines (hardware variants prior to final processing) - Newcastle University [15] 


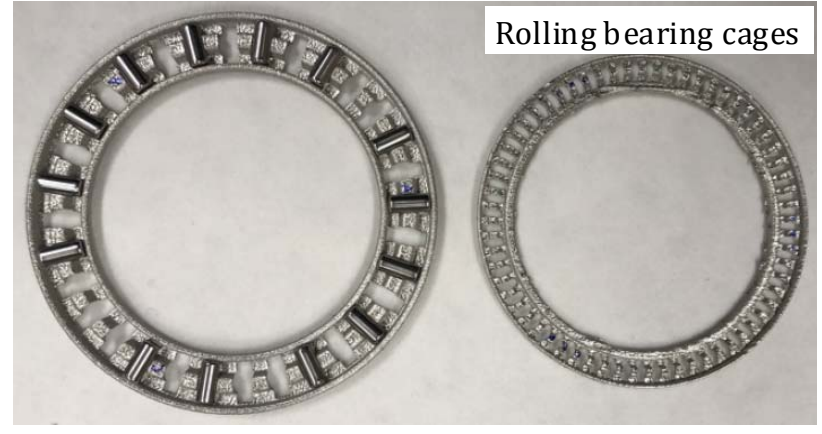

Fig. 5. Examples of rolling bearing cages fabricated using AM - Oak Ridge National Laboratory [16]

Fig. 4c) presents a family of heat guides (HGs) developed to enhance heat removal directly from the winding body [15]. AM has been used here to enable design solutions with high thermal conductivity and minimal additional power loss. As the HGs were designed to be placed in the stator slots, and consequently to be in direct contact with the winding body, providing a good balance between thermal and electrical properties of such an assembly was essential. It has been shown that the supplementary heat path between winding and the actively cooled machine housing (path introduced by HGs) results in $20 \%$ to $40 \%$ improvement in dissipation of the generated power loss from the stator/winding assembly [15]. Here, the lower improvement bound corresponds with a higher operating frequency, whereas the higher performance increase is at low frequency.

Rolling bearings are another important mechanical part, of the electrical machine assembly. There also has been some attention related to rolling bearings in the context of AM. These high-precision components would not normally be associated with AM. This is due to limitations of the existing AM technology. Nevertheless, the available literature shows feasibility work on low-volume fabricating of roll-bearings using AM [16], [17]. Examples of rolling bearing cages from the study are shown in Fig. 5. The stainless steel (316L) was used in AM. The initial outcomes showed that the surface finish of parts is one of the numerous challenges when considering AM of rolling bearings. Even though the initial results are far from being perfect, large companies supplying high-precision components have been working on developing such technology [17].

\section{B. Core and PM Magnetic Materials}

The magnetic materials are essential in the construction of modern, high-specific-output electrical machines. The existing methods for fabricating magnetic cores employ a wide range of electrical steels and soft magnetic composites (SMCs). A magnetic core is usually formed by stacking a set of appropriately prepared profiles/lamination sheets of an electrical steel or by compression moulding of a composite powdered metal and insulating agent [18]. Typically, two characteristic kinds of electrical steel are used: $\mathrm{FeSi}$ and $\mathrm{FeCo}$. The silicon based steels are the most common, whereas cobalt steels are employed for lower volume, more demanding applications. When considering a particular magnetic core

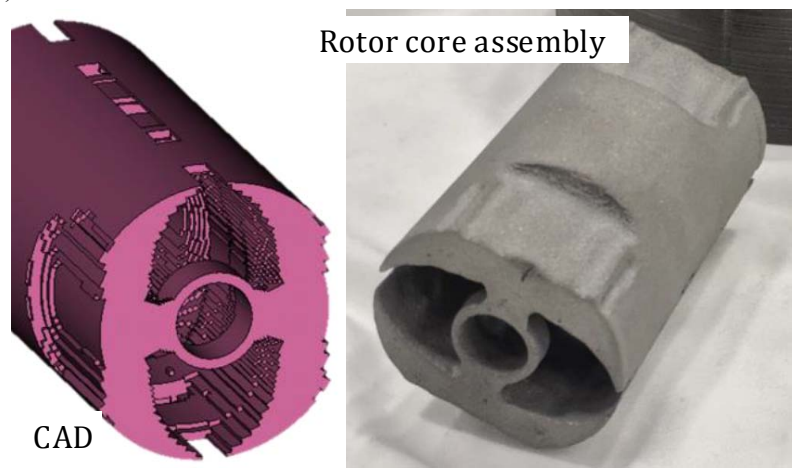

b)

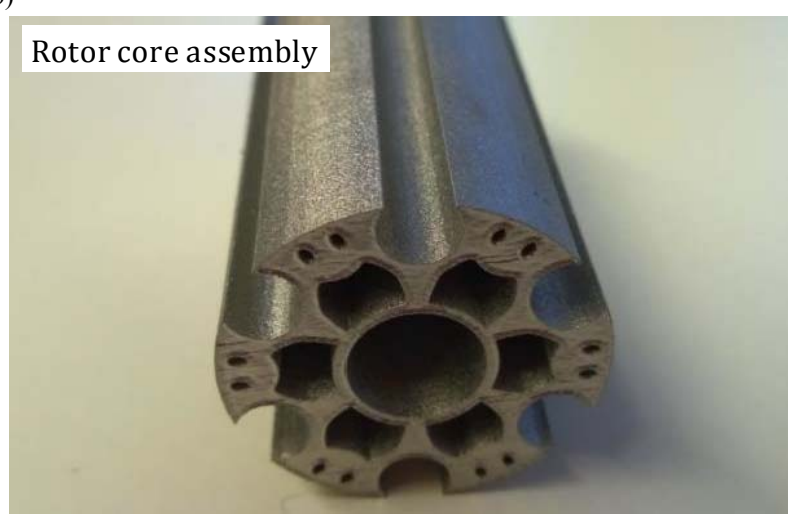

c)

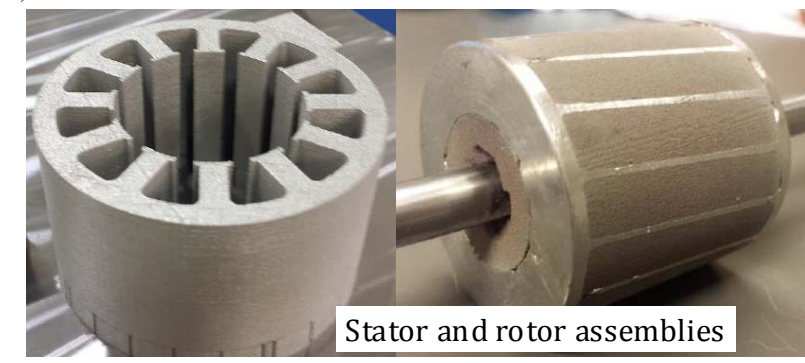

d)

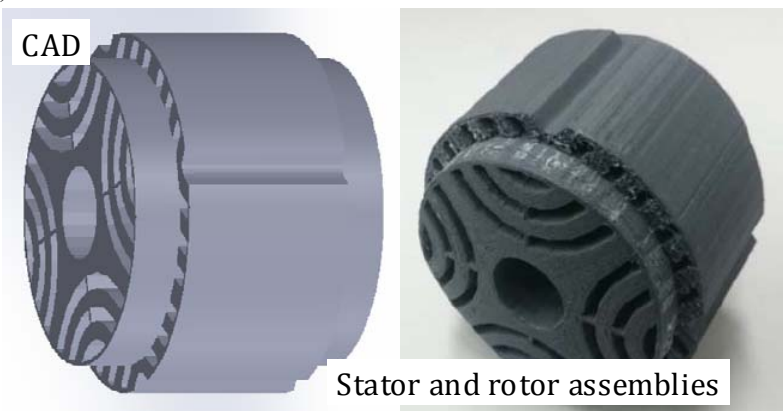

Fig. 6. Examples magnetic cores fabricated using AM, a) rotor prototype for a surface mounted PM machine - University of Nottingham [19], b) rotor prototype for a switched reluctance motor - VVT Technical Research Centre of Finland Ltd. [20] c) stator and rotor hardware for an induction machine - Oak Ridge National Laboratory [21], CAD and hardware of rotor and stator core packs for a line start synchronous reluctance machine National Cheng Tung University [22]

design, a number of material performance measures need to be accounted for. These include electromagnetic properties like magnetic saturation, magnetic permeability and specific power loss, and mechanical properties including yield strength, thermal expansion and resilience to thermal cycling. 
In this context, AM presents an interesting alternative to the well-established techniques for fabricating of magnetic parts and components. The research work related with this particular theme is rather broad, with a few interesting examples discussed in this section [19]-[26]. Fig. 6a) presents both optimised $\mathrm{CAD}$ and prototype of a rotor core pack for a surface mounted (SM) PM machine, as part of a design exercise. However, the main research effort has been placed on developing a suitable material and associated with AM processes to produce parts with 'good' magnetic properties [19]. It has been shown that the proposed process assures magnetic material with some of the properties to be comparable with the commercially available electrical steels like JNEX Super Core [19], [27]. Interestingly, the new material has relatively high $6.9 \%$ silicon content as compared with $6.5 \%$ for JNEX Super Core. However, the specific loss is four times higher for the developed material. With that being said, the specific power loss data is provided for a relatively low operating frequency of $50 \mathrm{~Hz}$. The mechanical properties of the material have not be explored in detail. A 50\% reduction in mass of the rotor magnetic core shown in Fig. 6a) has been achieved by combining the developed material, manufacturing process, electromagnetic and mechanical design-optimisation [19].

Fig. 6b) shows rotor hardware designed for a lightweight, high-specific-output switched reluctance machine [28]. In contrast to the previous example, here the rotor core pack was manufactured using FeCo [20]. The material chemical composition, together with appropriate fabricating and postprocessing, e.g. Hiperco50, offers the highest magnetic saturation among commercially available electrical steels [29]. The experimental data from tests on materials samples fabricated using AM have shown that electromagnetic properties are comparable with the equivalent electrical steel, e.g. magnetic saturation 2.3T (AM material) versus $2.4 \mathrm{~T}$ (Hiperco 50) and similar mechanical properties subject to a specific annealing procedure [20]. Also, the authors mention that the electrical resistivity of the developed samples could be further improved to reduce the specific power loss.

The next two examples presented in Figs. 6c) and 6d) illustrate parts of two different machine topologies: an induction machine with a cast aluminium squirrel cage [21] and a line start synchronous reluctance machine [22]. In both cases the research focus was placed on AM of the machine parts, with limited information on the machine performance gains achieved by employing AM. All the above examples of using AM in construction of the soft magnetic parts show different levels of maturity. They start with the detailed research on metallurgical aspects of material processing when using AM [19] and finish with design exercises showcasing capabilities and potential benefits of AM in application to electrical machines [20]-[22]. There is no evidence as yet of a complete machine assembly, with parts of the magnetic circuit being fabricated using AM, and experimentally derived performance measures of such a machine build.

Hard magnetic materials like rare-earth (RE) high-energy product PMs have become essential in developing compact and high-specific-output electrical machines.

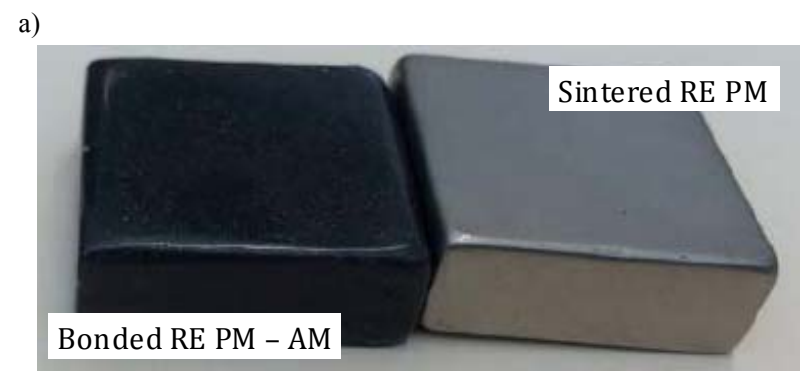

b)

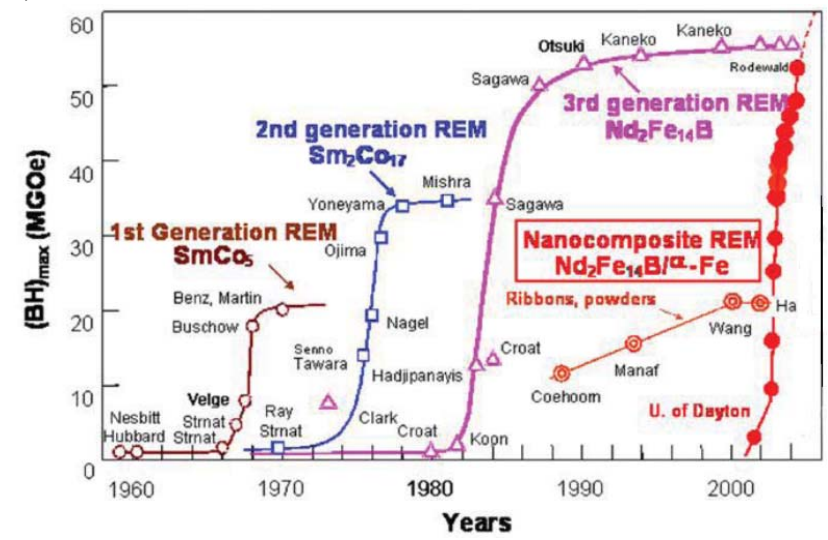

Fig. 7. PM and AM technology, a) example of PM fabricated using binder jet AM coated with polyurethane and nickel coated commercially sintered NdFeB - Oak Ridge National Laboratory [30], b) evolution of RE PMs with nanocomposites promising significant improvement in PM energy product - NASA Glenn Research Centre [35]

Two types of rare-earth PMs: NdFeB and SmCo have been used in a variety of demanding applications. Other, lower energy-density PMs like Ferrites, AlNiCo or MnAlC have also been widely explored in construction of electrical machines. However, the low-cost PM types offer lesser overall performance gains, and consequently their use is limited to specific applications. As the PM cost is an important factor when considering in-volume manufacturing, there has been continuous interest and development to improve both PM material utilisation and material physical properties.

$\mathrm{NdFeB}$ is usually manufactured in sintered or bonded form. The second type is particularly well suited for AM [30]-[34]. Typically bonded PMs are fabricated using compaction or injection moulding using thermoset or thermoplastic binder. Fig. 7 a) shows an example of PM fabricated using AM and more conventional sintering [30]. Both binder jet and big area additive manufacturing (BAAM) have been employed here to evaluate manufacturing of near-net-shape bonded $\mathrm{NdFeB}$ PMs. Both magnetic and mechanical properties of the PMs fabricated using BAAM are better or comparable with the more common injection moulded PMs [30]. Here, a combination of $\mathrm{NdFeB}$ and polyamide (Nylon-12) achieved PMs with energy product of $43.5 \mathrm{~kJ} / \mathrm{m}^{3}$ and remanence equal to $0.5 \mathrm{~T}$ using BAAM.

The AM of non-RE has also been undergoing some interesting developments [31]. Both AlNiCo and MnAlC types of PMs have been trialled using AM. More specifically, AlNiCo PMs used a laser engineered net shaping (LENS) system. It has been shown that the magnetic properties of LENS fabricated AlNiCo PMs are similar or better to the 
counterparts manufactured using more conventional casting or sintering. Here, the achieved remanence and coercivity are equal to $0.9 \mathrm{~T}$ and $-161.5 \mathrm{kA} / \mathrm{m}$ [31], [34]. When it comes to MnAlC PMs, the initial results have shown that manufacture of solid material samples is possible. However, the EBM process used in fabricating trials of the PMs will require fine tuning [31].

Further to exploring the existing PM types as disused above, there have been some interesting developments related with PM material science. More specifically nanocomposite exchange spring PMs, potentially offering performance better than the existing state-of-the-art sintered RE PMs [35]-[37]. Such PM material requires enhancing of a remnant magnetisation by a high magnetisation soft phase such as iron. At the same time a hard magnet phase with large uniaxial anisotropy provides a high intrinsic coercivity [36]. The most recent studies suggest that the nanocomposite PMs are capable of achieving energy product of $85.2 \mathrm{MGOe}\left(678 \mathrm{~kJ} / \mathrm{m}^{3}\right)$ as compared the existing sintered $\mathrm{NdFeB}$ with $64 \mathrm{MGOe}$ $\left(515 \mathrm{~kJ} / \mathrm{m}^{3}\right)$ [36]. Fig. $\left.7 b\right)$ illustrates evolution of RE PMs showing that the PM nanocomposite technology offeres significant improvement. To date, only thin and/or thick film processing methods allowed fabricating nanocomposite PMs.

\section{Windings and Electrical Insulation Materials}

The motor winding assembly consists of several key components: usually these include the electrical conductors, electrical insulation system and mechanical retention. The most common conductor materials used in constructing electrical windings are copper and aluminium, with copper being the most popular, mainly due to its relatively high electrical conductivity (58MS/m, 100\% IACS - International Annealed Copper Standard). The winding conductors are usually coated with an appropriate material, providing the required electrical, thermal and mechanical properties, e.g. voltage rating, thermal class and resilience to mechanical stress among others. To further improve these physical properties, the winding body is frequently impregnated and protected with appropriate lining materials, when fully formed.

A high conductor fill factor is frequently considered to be indicative of a 'good', low-loss winding design. However, when reviewing the modern machine designs with high-speed, high-frequency operation, the ac winding effects like skin, proximity and others, also need to be accounted for. These further complicate the winding design, where the conductor profile, arrangement and lay in the stator or rotor slots are of particular importance. Consequently, the conductor fill factor and overall winding power loss is usually compromised to mitigate the ac winding effects. In this context, the use of AM enables new design solutions, with improved performance measures, material utilisation and manufacturability as compared with commonly used methods for manufacturing windings.

Fig. 8a) presents a coil example designed for a filter inductor, where the individual coil turns have different profile [38]. This is to provide a low-loss winding design, where both $\mathrm{dc}$ and ac winding loss components are well balanced. This a)

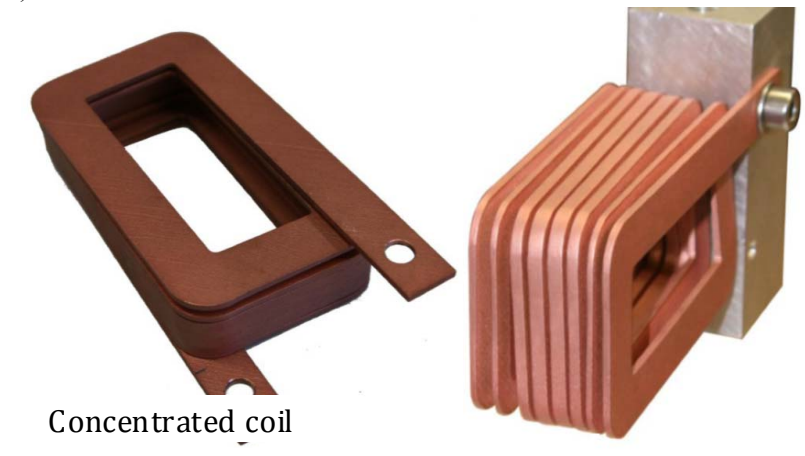

b)

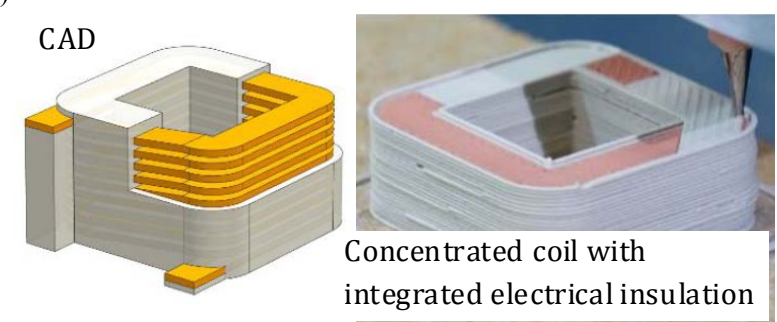

c)

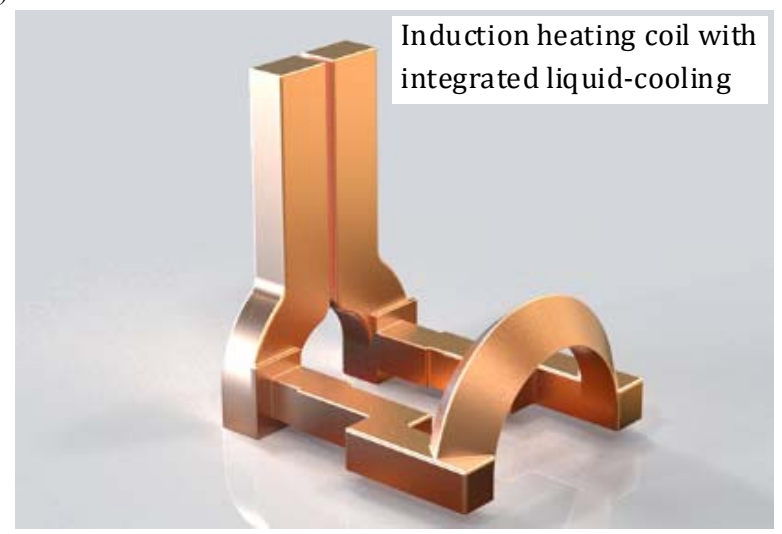

Fig. 8. Examples of electrical windings/coils fabricated using AM, a) 'variable' profile copper coil for concentrated windings - University of Bristol [38], b) MM copper coil with ceramic insulation for SRM Chemnitz University of Technology [40], c) liquid cooled induction coil for metal hardening process - GKN [41]

early feasibility study used DMLS and a copper alloy to fabricate the coil. However, the electrical material properties of the AM coil were found to be significantly poorer than the equivalent copper commonly used in fabricating coils. Here, the authors reported electrical conductivity to be $\% 51$ IACS, which is even lower than that of aluminium conductors. Further work by the same authors has shown significant improvement in electrical conductivity of the coil material (43.5MS/m, 75\% IACS) for CuCr1Zr (C18150) [39]. The above examples of coils fabricated using AM required further processing, which included coating with an appropriate electrical insulation (enamel) [38], [39]. This additional stage in the manufacturing process has been addressed in [40]. Here the authors used a multi-material (MM) AM to fabricate copper winding with ceramic insulation for a highperformance switched reluctance (SRM) machine. Fig. 8b) shows example of an individual coil, the CAD and prototype hardware. The AM employed by the authors used both copper alloy and a ceramic material with an appropriate binding agent 
[40]. Such an approach enables complex geometries to be formed. An appropriate thermal treatment, during which built parts are sintered, has been used to achieve the required material physical properties. The electrical conductivity of the fabricated coils was lower than the conventional copper wire (41.9MS/m, 72\% IACS), which is attributed here to the material porosity [40]. Further to this, the authors investigated thermal expansion of the multi-material parts showing no mechanical defects after an initial thermal cycling up to $300^{\circ} \mathrm{C}$.

Fig. 8c) presents an interesting example of an induction heating coil used for hardening of parts in metal processing [41]. The coil is liquid cooled and made of copper. This commercial application of AM has shown numerous benefits compared with existing solutions. These include improved repeatability of the hardening process, longer in-service life and shorter setting up time among others. Although, the above examples is not directly related to electrical machine technology, it highlights the potential of AM beyond research studies.

As has been outlined in the previous sections, the post processing of AM parts is very important. It allows for the required material physical properties to be altered to a certain degree. The winding/coil manufacture is governed by the same rules. In [42] the authors assess different material post processing/heat treatment techniques and their influence on mechanical and electrical properties of conductors fabricated with aluminium alloy AlSiloMg. The experimental data illustrate that AM introduce inherent material anisotropy to the fabricated parts. This is particularly interesting material physical property when considering winding designs for highfrequency applications.

The MM AM of windings/coils with electrical insulation and other machine subassemblies is very desirable, allowing potential reduction or even elimination of various processes used in the conventional manufacturing of electrical machines. The existing research related to MM AM includes: polymers and composites, metals and alloys, and multifunctional metal-ceramic structures [43]. In the context of electrical machines, MM AM is rather limited to the examples already discussed earlier in the paper [40], [44]. Note that the authors are aware of numerous of research and development activities devoted to MM AM, results of which are not readily available yet.

\section{OBSERVATIONS AND COMMENTS}

It was rather difficult to make a clear judgment on the technology trends or limitations at the moment of drafting this review paper. The existing literature related to AM of electrical machines shows a varied level of technology maturity for the key machine subassemblies. The most advanced appear to be the structural and thermal management implementations, whereas active components are some way behind. The ongoing research into AM for electrical machines has been focused on tackling individual machine subassemblies/active materials in a decoupled manner to a large extent. Although, AM provides a virtually unrestricted a)

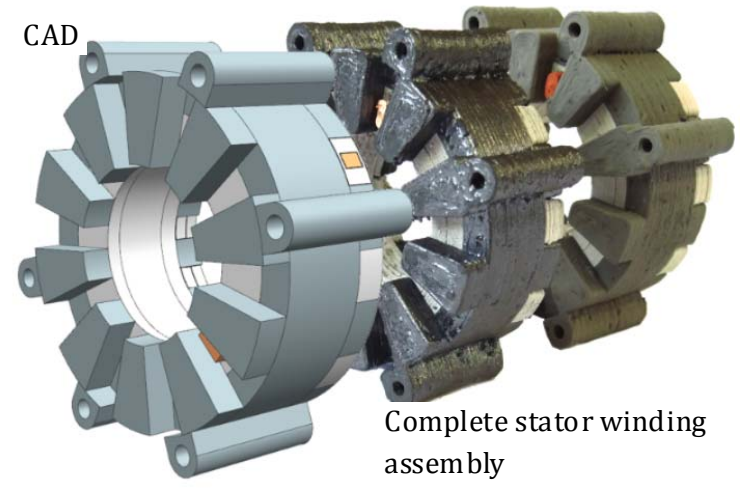

b)

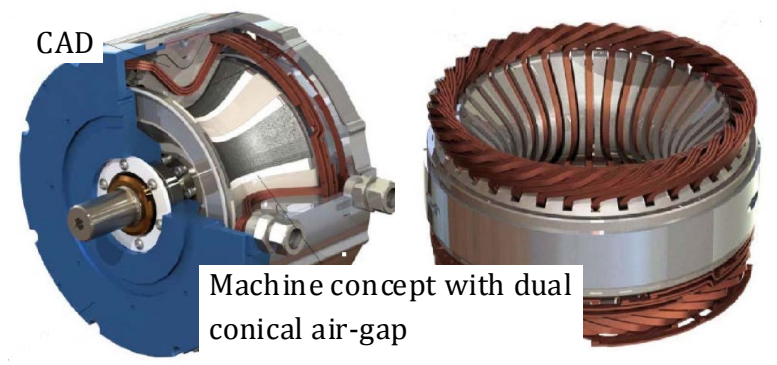

Fig. 9. Examples of electrical machine assemblies fabricated using AM, a), complete stator-winding assembly - Chemnitz University of Technology [44], b) a new machine concept with conical air-gap - Persimmon Technologies Corporation [45]

way of designing and manufacturing new components, there is a need to understand how this translates to successful implementation when it comes to in-volume manufacturing of electrical machines. Several aspects including: materials, manufacturing techniques and new design concepts fully utilising AM needs to be considered. A more comprehensive design approach seems a natural step forward in developing AM of the next generation of electrical machines. Some of the early examples of MM AM of integrated machine subassemblies or new machine concepts look very interesting indeed, Fig. 9. However, AM of electrical machines is not limited to the machines themselves. Integrating power electronics with electrical machines using AM technology is another exciting prospect.

\section{ACKNOWLEDGMENT}

The authors wish to thank Advanced Propulsion Centre (APC) UK for supporting this research.

\section{REFERENCES}

[1] (2018, November). "GE to install first metal additively manufactured part on GEnx commercial airline engines," Metal Additive Manufacturing, vol. 4, no. 4, pp. 10

[2] (2018, September). "Airbus Helicopters begins high-volume metal Additive Manufacturing," Metal Additive Manufacturing, vol. 4, no. 3, pp. 36.

[3] (2013, September). "Standard Terminology for Additive Manufacturing Technologies," ASTM standard (Designation: F2792 - 12a), pp. 1 - 2 .

[4] (2018, June). "Standardization Roadmap for Additive Manufacturing," America Makes \& ANSI Additive Manufacturing, pp. $1-269$.

[5] F. Petzoldt, C. Aumund-Kopp, "Standards for metal Additive Manufacturing: A global perspective," Metal Additive Manufacturing, 
vol. 2 , no. 2 , pp. $45-52,2016$.

[6] J. Isaza, C. Aumund-Kopp, "Additive Manufacturing with metal powders: Design for Manufacture evolves into Design for Function," Powder Metallurgy Review, vol. 3, no. 2, pp. 41 - 50, 2014.

[7] O. Wallmark, "Investigation of additive manufacturing of electric machine components for EV," Report, Swedish Electromobility Centre, 2018

[8] (2018, November). "Mitsubishi Electric reveals new Dot Forming Technology for metal Additive Manufacturing," Metal Additive Manufacturing, vol. 4, no. 4, pp. 39.

[9] (2018, November). "Trumpf adds high-strength tool steel processing and green laser functionality for AM," Metal Additive Manufacturing, vol. 4 , no. 4 , pp. 16 .

[10] "Additive Manufacturing moves TUfast," [Online], Available: https://additivenews.com/additive-manufacturing-moves-tufast/

[11] "Nottingham PhD student wins Additive World Design Challenge award," [Online], Available: https://exchange.nottingham.ac.uk/blog/ phd-student-wins-additive-world-design-challenge-award/

[12] S. Lammers, G. Adam, H. J. Schmid, R. Mrozek, R. Oberacker, M. J. Hoffmann, F. Quattrone, B. Ponick, "Additive Manufacturing of a lightweight rotor for a permanent magnet synchronous machine," 6th International Electric Drives Production Conference (EDPC), pp. 41 $45,2016$.

[13] W. Sixel, M. Liu, G. Nellis, B. Sarlioglu, "Cooling of Windings in Electrical Machines via 3D Printed Heat Exchanger," IEEE Energy Conversion Congress and Exposition (ECCE), pp. 229 - 235, 2018.

[14] R. Wrobel, B. Scholes, A. Hussein, A. Mustaffar, S. Ullah, D. Reay, B. Mecrow, "Design and Experimental Characterisation of an Additively Manufactured Heat Exchanger for an Electric Propulsion Unit of a High-Altitude Solar Aircraft," IEEE Energy Conversion Congress and Exposition (ECCE), (in press).

[15] R. Wrobel, A. Hussein, "Design Considerations of Heat Guides Fabricated Using Additive Manufacturing for Enhanced Heat Transfer in Electrical Machines," IEEE Energy Conversion Congress and Exposition (ECCE), pp. 6506-6513, 2018.

[16] B. Richardson, L. Love, J. G. Tate, "Additive Manufacturing for Low Volume Bearings," Crada Final Report: NFE-16-06278, Oak Ridge National Laboratory, 2017.

[17] (2018, December). "Schaeffler and DMG MORI look to Additive Manufacturing for development of rolling bearings," Metal Additive Manufacturing, vol. 2, no. 3, pp. 21.

[18] H. Shokrllahi, K. Janghorban, "Soft magnetic composite materials (SMCs)," Journal of Materials Processing Technology, Elsevier, vol. 189, no. 2, pp. 1 - 12, February 2007.

[19] G. Garibaldi, "Laser additive manufacturing of soft magnetic cores for rotating machinery: materials development and part design," $P h D$ thesis, University of Nottingham, UK, 2018.

[20] S. Metsa-Kortelainen, T. Lindroos, M. Savolainen, A. Jokinen, A Revuelta, A. Pasanen, K. Ruusuvuori, J. Pippuri, "Manufacturing of topology optimized soft magnetic core through 3D printing," NAFEMS Nordic Seminar, 2016

[21] M. Chinthavali, "Additive Manufacturing Technology for Power Electronics Applications," IEEE Applied Power Electronics Conference and Exposition (APEC), 2016.

[22] Z.-Y. Zhang, K. J. Jhong, C.-W. Cheng, P.-W. Huang, M.-C. Tsai, W.H. Lee, "Metal 3D printing of synchronous reluctance rotor," IEEE International Conference on Industrial Technology (ICIT), pp. 1125 1128,2016

[23] Y. Yan, "Design Methodology and Materials for Additive Manufacturing of Magnetic Components," $P h D$ thesis, Virginia Polytechnic Institute and State University, Blacksburg, VA, USA, 2017.

[24] Y. Yan, C. Ding, K. D. T. Ngo, Y. Mei, G.-Q. Lu, "Additive manufacturing of planar inductor for Power Electronics applications," IEEE International Symposium on 3D Power Electronics Integration and Manufacturing (3D-PEIM), pp. 1 - 4, 2016.

[25] C. V. Mikler, "Laser Additive Manufacturing of Magnetic Materials," MSc thesis, University of North Texas, TX, USA, 2017.

[26] N. C. Benack, T. Wang, K. Matthews, M. L. Taheri, "Additive Manufacturing Methods for Soft Magnetic Composites (SMCs)," Microscopy and Microanalysis, Cambridge University Press, vol. 24, no. 6, pp. $1-2$, December 2018.

[27] (2019, January). "Super Core Electrical steel sheets for high-frequency application," Data sheet JFE Steel Corporation, [Online], Available: http://www.jfe-steel.co.jp/en/products/electrical/catalog/fle-002.pdf.
[28] J. Lee, J. H. Seo, N. Kikuchi, "Topology optimization of switched reluctance motors for the desired torque profile," Structural and Multidisciplinary Optimization, Springer, vol. 42, no. 5, pp. 783 - 796, November 2010.

[29] (2019, January). “Alloy Data, Hiperco 50 Alloy," Data sheet Carpenter, [Online], Available: https://www.cartech.com/en/product-solutions/ cartech-hiperco-50-alloy/.

[30] M. P. Paranthaman, "Additive Manufacturing for Isotropic NdFeB Bonded Permanent Magnets," Crada Final Report: NFE-15-05761, Oak Ridge National Laboratory, 2016.

[31] V. Popov, A. Koptyug, I. Radulov, F. Maccari, G. Muller, "Prospects of additive manufacturing of rare-earth and non-rare-earth permament magnets," $15^{\text {th }}$ Global Conference on Sustainable Manufacturing, Procedia Manufacturing, Elsevier, vol. 21, pp. 100 - 108, 2018.

[32] V. T. Nguyen, F. Calvayrac, A. Bajorek, N. Randtianantoandro, "Mechanical alloying and theoretical studies of $\mathrm{MnAl}(\mathrm{C})$ magnets," Journal of Magnetism and Magnetic Materials, Elsevier, vol. 462, pp. $96-104,2018$

[33] J. Jacimovic, F. Binda, L. G. Herrmann, F. Greuter, J. Genta, M. Calvo, T. Tome, R. A. Simon, "Net Shape 3D Printed NdFeB Permanent Magnet," Advanced Engineering Materials, vol. 18, pp. 1 - 9, November 2016.

[34] E. M. H. White, A. G. Kassen, E. Simsek, W. Tang, R. T. Ott, I E. Anderson, "Net Shape Processing of Alnico Magnets by Additive Manufacturing," IEEE Transactions on Magnetics, vol. 53, no. 11, pp. $1-6,21$ November 2017

[35] A. Misra, "Nano-Magnets and Additive Manufacturing for Electric Motors," $8^{\text {th }}$ Annual CAFE Foundation Electric Aircraft Symposium, Presentation - NASA Glenn Research Centre, 2014.

[36] M. P. Paranthaman, I. C. Nlebedim, F. Johnson, S. K. McCall, “Additive Manufacturing of Permanent Magnets," Materials Matters, vol. 11, no. 4, pp. $1-19,2016$.

[37] "The Exchange-Spring Magnet: A New Material Principle for Permanent Magnets," IEEE Transactions on Magnetics, vol. 27, no. 4, pp. $3588-3600$, July 1991.

[38] N. Simpson, P. H. Mellor, "Additive Manufacturing of Shaped Profile Windings for Minimal AC Loss in Gapped Inductors," IEEE Energy Conversion Congress and Exposition (ECCE), pp. 1 - 7, 2017.

[39] N. Simpson, P. H. Mellor, "Additive Manufacturing of Shaped Profile Windings for Minimal AC Loss in Electrical Machines," IEEE Energy Conversion Congress and Exposition (ECCE), pp. 5765 - 5772, 2018.

[40] F. Lorenz, J. Rudolph, R. Werner, "Design of 3D printed High Performance Windings for Switched Reluctance Machines, "Internation Conference on Electrical Machines (ICEM), 2451 - 2457, 2018.

[41] (2018, July). "GKN Powder Metallurgy identifies potential of metal AM for production of copper induction coils," Metal Additive Manufacturing, vol. 4, no. 3, pp. 32.

[42] C. Silbernagel, I. Ashcroft, P. Dickens, M. Galea, "Electrical Resistivity of Additively Manufactured AlSi10Mg for Use in Electric Motors," Additive Manufacturing, Elsevier, vol. 21, pp. 395 - 403, May 2018.

[43] A. Bandyopadhyay, B. Heer "Additive manufacture of multi-material structures," Material Science and Engineering Reports, vol. 129, pp. 1 16, April 2018.

[44] "Multi-material 3D printing," [Online], Available: https://www.tuchemnitz.de/etit/ema/AMMM/index.php

[45] J. Krishnasamy and M. Hosek, "Spray-formed hybrid-field traction motor," SAE World Congress Experience, pp. 1-7, 2017.

\section{BIOGRAPHIES}

Rafal Wrobel (SM'13) received the M.Sc.Eng. degree from the Opole University of Technology, Opole, Poland, in 1998; the Ph.D. degree from the Lodz University of Technology, Lodz, Poland, in 2000; and the habilitation degree from Opole University of Technology, Opole, Poland, in 2013. He is a Senior Research Associate at Newcastle University, Newcastle upon Tyne, UK. His research interests include multidisciplinary 'design for application' of electrical machines, transformers and wound passive components.

Barrie Mecrow received the Ph.D. degree in electrical engineering from Newcastle University, Newcastle upon Tyne, UK in 1986. He was a Turbo Generator Design Engineer at NEI Parsons, Newcastle upon Tyne, UK. In 1987, he became a Lecturer and in 1998 a Professor at Newcastle University. His research interests include fault-tolerant drives, high performance permanent magnet machines, and novel switched reluctance drives. 